\title{
Da Viabilidade de um Projeto de Governabilidade Tecnocrata: proposta de Emenda Constitucional no 194/2016 - a PEC do diploma
}

\author{
Of the Feasibility of a Technocrat Governability Project: proposed amendment to the \\ Constitution number 194/2016 - the PEC of the diploma
}

Ronaldo de Albuquerque Agra

Resumo: Em 15 de março de 2016, o Deputado Irajá Abreu (PSD-TO) apresentou proposta de emenda à Constituição (PEC) para exigir dos candidatos aos cargos do Executivo e do Legislativo formação acadêmica de nível superior. Sugere que o diploma universitário torna o representante mais preparado ao exercício da função pública, no entanto, essa ideologia tecnocrata diante da elevada taxa de analfabetismo no Brasil torna ineficaz a aplicação da PEC e ainda atenta contra a soberania popular. Pautado nos dados estatísticos e nas pesquisas bibliográficas, analisaremos a viabilidade da aprovação dessa PEC, ponderando os argumentos favoráveis e contrários, tendo como norte a soberania popular e o princípio constitucional representativo. $\mathrm{O}$ método de abordagem foi o hipotético-dedutivo. O método de procedimento foi o estatístico-comparativo. As técnicas de pesquisa utilizada foram a documental e bibliográfica. A revisão bibliográfica teve supedâneo em obras doutrinárias e artigos extraídos de sites da internet.

Palavras-chave: Tecnocracia. Democracia. Proposta de Emenda Constitucional. Diploma.

\begin{abstract}
On March 15, 2016, Deputy Irajá Abreu (PSD-TO) presented a Proposed Amendment to the Constitution (PEC) which requires a University Degree for candidates of Executive and Legislative positions. It suggests that a Diploma makes the representative more prepared to perform public positions; however, this technocratic ideology, in view of the high illiteracy rate in Brazil, renders ineffective the application of the PEC and, moreover, undermines popular sovereignty. Based on statistical data and bibliographical research, we will analyze the feasibility of approving this PEC, pondering the favorable and contrary arguments, based on popular sovereignty and the constitutional principle of representation. The method of approach was hypothetic-deductive. The procedure method was statistical-comparative. The research techniques used were documentary and bibliographical. The bibliographical revision was based on doctrinal works and articles extracted from Internet sites.
\end{abstract}

Keywords: Technocracy, Democracy, Proposal for Amendment to the Constitution, University Degree.

Artigo recebido em 13 set. 2016 e aprovado em 22 dez. 2016. 


\section{Introdução}

Almejando elevar o nível intelectual dos parlamentares e dos chefes do Executivo, em todos os escalões do governo, o Deputado Irajá Abreu (PSD-TO) apresentou proposta de emenda à Constituição: a PEC no 194/2016. Conhecida como "A PEC do Diploma", o autor pretende criar uma nova condição de elegibilidade, exigindo formação acadêmica de nível superior aos pretendentes aos cargos dos Poderes Legislativo e Executivo.

Considerando os argumentos favoráveis e contrários à proposta, faremos uma breve análise crítica sobre sua eficácia e viabilidade, por meio de pesquisas bibliográficas, fontes históricas e dados estatísticos, os quais refletem o atual panorama do nível educacional da sociedade brasileira (ressalta-se: no processo de elaboração de leis, o legislador deve ter sensibilidade para identificar os problemas sociais e elaborar normas eficazes à solução dos conflitos, aspirando a pacificação social, a justiça e o bem comum).

Ao final, estabeleceremos um paradigma entre o método de elaboração de um projeto de inovação tecnológica e o processo de elaboração de um projeto-lei, propugnando pela paridade de ambos, ressaltando o papel das Comissões de Constituição, Justiça e Cidadania no controle preventivo de constitucionalidade das leis.

\section{A PEC do Diploma}

A proposta de emenda à Constituição objeto do presente estudo (PEC nº 194/2016, apresentada em 15 de março de 2016 pelo Deputado Irajá Abreu, PSD-TO), referente à exigência do curso de nível superior, em qualquer área, àqueles que desejam disputar aos cargos de Senador, Deputado Federal, Estadual ou Distrital, Presidente, Vice-Presidente, Governador, Vice-Governador, Prefeito, Vice Prefeito e Vereador, possui como texto:

As Mesas da Câmara dos Deputados e do Senado Federal, nos termos do $\int 3^{\circ}$ do art. 60 da Constituição Federal, promulgam a seguinte emenda ao texto constitucional:

Art. $1^{\circ}$ Esta Emenda Constitucional acrescenta inciso ao art. 14, $₫ 3^{\circ}$, da Constituição Federal, para exigir conclusão de curso de graduação de nível superior em qualquer área como condição de elegibilidade para os cargos de Senador, Deputado Federal, Estadual ou Distrital, Presidente, Vice-Presidente, Governador, Vice-Governador, Prefeito, Vice-Prefeito e Vereador. 
Art. $2^{\circ} \mathrm{O}$ art. $14, \int 3^{\circ}$, da Constituição Federal, passa a vigorar acrescido do seguinte inciso:

"Art. 14

$\int 3^{0}$

VII - conclusão de curso de graduação de nível superior em qualquer área, para os cargos de Senador, Deputado Federal, Estadual ou Distrital, Presidente, Vice-Presidente, Governador, Vice-Governador, Prefeito, Vice-Prefeito e Vereador.

Art. $3^{\circ}$ Os detentores de mandato eletivo de Senador, Deputado Federal, Estadual ou Distrital, e Vereador na data da publicação desta Emenda Constitucional não estão sujeitos à condição prevista no art. 14, \ 3ํ, VII, da Constituição Federal, para candidatarem-se à reeleição para os mesmos cargos.

Art. $4^{\circ}$ Esta Emenda Constitucional entra em vigor na data de sua publicação.

(NR).

A justificativa dessa proposta consubstancia-se na necessidade de que seja estabelecido um patamar superior àqueles que pretendem concorrer aos cargos eletivos.

O Deputado Irajá Abreu (PSD-TO) alega ser necessário que na busca de soluções dos problemas nacionais, o candidato possua uma visão mais profunda da realidade brasileira, algo que a experiência acadêmica propicia com maior efetividade. E prossegue:

No tocante ao Poder Legislativo, essa proposta busca elevar o nível dos debates e da legislação produzida em todas as unidades federativas, na medida em que seus membros passarão a deter conhecimentos suficientes para desempenhar, de modo efetivo, as suas prerrogativas.

Pelo exposto, observa-se que o intuito do parlamentar é a formação de um governo especializado (tecnocrata), tendo por escopo a prestação de um serviço eficiente aos administrados. 


\section{Tecnocracia: Conceito e Origem}

O termo tecnocracia deriva das palavras gregas tekhne, que significa técnica, destreza, habilidade ou aptidão, ao passo que kratos designa governo. Tecnocracia é, portanto, literalmente, "governo técnico".

O pensamento tecnocrata se origina nas raízes da Escola de Pitágoras, cujo projeto era implantar "o Governo dos Sábios”. Encontramos resquícios da tecnocracia na democracia representativa, proveniente do governo representativo que as revoluções liberais começaram a implantar pelo mundo, a partir do último quartel do século XVIII (FERREIRA FILHO, 2005. Pág. 83).

Montesquieu afirmou na obra "Do Espírito das Leis" que: "um dos grandes inconvenientes da democracia é a falta de preparação do povo para discutir os assuntos públicos; desta forma, o povo deve participar do governo somente para eleger seus representantes" (MONTESQUIEU, 2005, pág. 171).

Na França iluminista, Sieyés defendeu perante a Assembleia Constituinte a necessidade de um governo representativo devido à "falta de instrução e de tempo da nação para poder ocupar-se adequadamente de assuntos públicos". Para Sieyés o povo não pode falar nem atuar senão por intermédio de seus representantes (SIEYÉS apud SARTORI, 1992, pág. 226).

A ideologia tecnocrata também foi citada no Capítulo LVII da obra "O Federalista", de 1788: "O fim de toda constituição política é, ou deveria ser, primeiramente, ter como governantes homens que possuam maior sabedoria para discernir e maior virtude para cuidar do bem público" (HAMILTON; MADISON; JAY, 1994, pág. 242).

Esse governo representativo era um sistema imaginado para institucionalizar a forma aristocrática de governo, visando conceder o efetivo exercício do poder à minoria dos mais capazes, eleitos pelo povo em geral.

A base fundamental da representação é a ideia exposta por Montesquieu de que os homens em geral não têm a necessária capacidade para bem apreciar e, consequentemente, bem decidir os problemas políticos. Assim, no interesse de todos, essas decisões devem ser confiadas aos mais capazes, aos representantes do povo.

A seleção da minoria governante era feita também por uma minoria dentre o povo, por intermédio do sufrágio censitário. Este, com efeito, excluía os mais pobres de qualquer participação política, graduando o di- 
reito de votar e a elegibilidade para os demais, em função de seu grau de riqueza - apenas os mais ricos tinham plena capacidade política.

Com o passar do tempo, porém, alcançou-se o sufrágio universal. De fato, a partir do fim do século XIX, abandonou-se o sufrágio censitário e os Estados passaram a dar o voto e a elegibilidade a todos os homens. Posteriormente, esse direito foi estendido às mulheres.

Com o sufrágio universal, os representantes vieram a ser escolhidos pelo povo; tomou-se o governo representativo o caráter democrático, denominando-se democracia representativa (espécie de democracia na qual o povo governa indiretamente, por intermédio de representantes que elege).

O jurista José Afonso da Silva (1996) é um ferrenho crítico desse modelo de democracia representativa, uma vez que se trata de uma visão elitista, denominando-a de elitismo democrático. Segundo essa doutrina, compete às elites a tarefa de promover o bem comum, mediante um processo de interação com a massa. Auscultando o povo, as elites nacionais identificam seus anseios e aspirações; possuindo maior conhecimento da realidade histórico-cultural e dos dados conjunturais, têm uma visão mais elaborada dos autênticos interesses nacionais. Cabe-lhes, assim, interpretar os anseios e aspirações, difusos no meio ambiente, harmonizando-os com os verdadeiros interesses da Nação e com o bem comum, apresentando-os, de volta, ao povo que, desse modo sensibilizado, poderá entender e adotar os novos padrões que lhe são propostos (DA SILVA, 1996, pág. 128).

Coerente com sua essência antidemocrática, o elitismo assenta-se em inerente desconfiança do povo, que reputa intrinsecamente incompetente. Por isso sua "democracia" sempre depende de pressupostos notoriamente elitistas, tais como: o de que o povo precisa ser preparado para a democracia; de que esta pressupõe certo nível de cultura, de amadurecimento social, de desenvolvimento econômico; reclama que o povo seja educado para ela (e outros semelhantes que, no fim das contas, preparam os fundamentos doutrinários do voto de qualidade e restritivo).

A contradição é evidente, pois supõe que o povo deve obter tais requisitos para o exercício da democracia dentro de regime não democrático; que as elites devem conduzi-lo à uma situação que se opõe aos interesses delas e as elimina. Teremos, enfim, a singularidade de aprender a fazer democracia em um laboratório não democrático. 


\subsection{A Tecnocracia no Brasil}

No Brasil a tecnocracia teve como precursor Abílio de Nequete ao fundar o Partido Tecnocrata em 1926, sob a máxima: "Técnicos de todos os países, uni-vos". Pregava um modelo de governabilidade funcional, com a aplicação das ciências no ciclo de todas as cadeias produtivas, a fim de garantir a sustentabilidade da espécie humana.

O ex-Presidente Getúlio Vargas adotou essa ideologia durante o Estado Novo, por ocasião da industrialização e das conquistas dos direitos trabalhistas no país. Na década de 30, Vargas já discursava que "a época era das assembleias especializadas e dos conselhos técnicos integrados à administração". Afirmava que "o Estado puramente político, no sentido antigo do termo, era uma entidade amorfa, que, aos poucos, vai perdendo o valor e a significação".

O aprofundamento da Tecnocracia se daria com João Goulart pelas reformas de base preconizadas no socialismo científico, mas o Golpe Militar em 1964 subverteu o projeto tecnocrata. Após o fim da Ditadura Militar houve iniciativas democráticas de partidos com traços tecnocratas, com o intuito de consolidar o Brasil como grande potência, a exemplo do PRONA (Partido de Reedificação da Ordem Nacional) de extrema-direita, extinto depois da morte do seu líder, Dr. Enéas Ferreira Carneiro.

\section{Tecnocracia Versus Democracia}

É salutar à Nação que o governo seja composto por cidadãos que possuam conhecimentos voltados às áreas administrativa, econômica, jurídica, tributária, uma vez que o político, na qualidade de agente, exerce o múnus público, pautado nos princípios da celeridade e da eficiência da Administração Pública.

Peter Drucker (1993) afirma em seus artigos científicos que o poder da informação como originária de ações de sucesso é essencial à criação e à permanência das organizações no mercado; quanto mais conhecimento, maiores são as chances de criar, planejar, controlar, solucionar ou oportunizar o momento (DRUCKER, 1993, pág. 02). Frederick Taylor (1990), o pai da Administração científica, acreditava que uma boa gestão, poderia fazer com que o trabalhador produzisse mais em menos tempo, sem elevar os custos de produção para uma empresa (TAYLOR, 1990, pág. 11). 
E Norberto Bobbio considera as transformações da sociedade civil como justificativa à instauração de um governo tecnocrata. Afirma que a passagem de uma economia familiar para uma economia de mercado e desta para uma economia protegida torna necessário constituir um quadro profissional habilitado a lidar com a complexidade social crescente (BOBBIO apud STRECK, 2010, pág. 116).

O projeto democrático, no entanto, é antitético ao projeto tecnocrático, e essa dicotomia se aflora com maior intensidade nos países subdesenvolvidos, onde a população não dispõe dos serviços básicos, como a educação, que deveria ser oferecida de forma adequada e satisfatória pelo Estado.

José Afonso da Silva (1996) preleciona que a tese inverte o problema, transformando em pressupostos da democracia as situações que se devem fazer parte de seus objetivos (educação, nível de cultura, desenvolvimento), que envolva a melhoria de vida, aperfeiçoamento pessoal, tudo que se amalgama com os direitos sociais, cuja realização cumpre ser garantida pelo regime democrático. Não são pressupostos desta, mas objetivos.

\section{Da Ineficácia da PEC 194/2016}

O jurista Pinto Ferreira afirma que em uma sociedade onde se cristaliza o binômio "exploradores versus explorados", não há uma autêntica democracia, porque via de regra a educação ainda é privilégio de classes ricas (FERREIRA, 1995, pág. 92).

Embora caiba razão ao autor da proposta quando afirma que o cidadão preparado possui maior facilidade de compreensão e de interpretação, e que com mais conhecimento pode melhor contribuir à sociedade no exercício do seu mandato, a criação dessa nova condição de elegibilidade configuraria um grande empecilho à concretização da democracia participativa, visto que é uma medida excludente e elitista, conforme o atual panorama da educação brasileira.

Miguel Reale vaticina que a regra de Direito é a indicação de um sentido que envolve sempre problemas de eficácia, ou seja, de correspondência necessária entre o seu enunciado e as conjunturas histórico-axiológicas, e que a eficácia se relaciona com a aplicabilidade ou executoriedade de uma norma vigente (REALE, 1994, pág. 606). É a "aptidão da norma para prodųir os efeitos que lhe são próprios” (NOVELINO, 2008, pág. 130). 
In casu, observa-se que a proposta de reforma não teria eficácia, porque, segundo levantamento feito pelo Instituto de Pesquisa Econômica Aplicada (IPEA), há cidades nordestinas onde quase a metade dos habitantes é analfabeta. A revista Exame, na edição de nº 1098, veiculada em 24 set. 2015, divulgou pesquisa realizada pelo IPEA que demonstrava elevado grau de analfabetismo em diversas cidades brasileiras, a maioria delas localizadas na região nordeste.

Os dados foram obtidos a partir de análise em 5,5 mil cidades brasileiras, sendo detectados, inclusive, os locais nos quais mais de $40 \%$ da população não sabe ler ou escrever um simples bilhete. Na maior parte desses municípios, o índice das crianças de 6 a 14 anos que não frequentavam rede de ensino supera a média nacional, a exemplo de Alto Alegre (RR), que é a cidade com mais crianças fora da escola - quase $45 \%$ delas não estudam.

A título de demonstração, abaixo o ranking com as dez cidades nas quais quase a metade da população é analfabeta:

1ำ Alagoinha do Piauí (PI) - 44,4\%

2-- Minador do Negrão (AL) - 43,8\%

3ำ- Caraúbas do Piauí (PI) - 43,8\%

4ํㅡ - Caxingó (PI) - 43,7\%

5o - Paquetá (PI) - 43,6\%

$6^{\circ}$ - Vera Mendes (PI) - 43,9\%

7o - Massapê do Piauí (PI) - 43,4\%

8 - Salgadinho (PE) - 43,2\%

9o - Pedro Régis (PB) - 42,8\%

$10^{\circ}$ - Traipu (AL) - 42,6\%

Em relação àqueles que possuem curso superior foi constatado que somente $16 \%$ dos trabalhadores conseguiram concluir a universidade. Esse baixo índice poderia inviabilizar as eleições, principalmente, em pequenas cidades, uma vez que o projeto exige formação acadêmica para todos os cargos políticos eletivos tanto do Poder Legislativo quanto do Executivo.

Segundo dados da Pesquisa Nacional de Domicílios (PNAD) divulgados pelo IBGE, nos três últimos meses de 2014, 3 em cada 10 pessoas da força de trabalho brasileira não tinham sequer concluído o ensino fundamental. A situação já era (é) pior na região nordeste, onde a maior parte 
da população ocupada $(40,7 \%)$ não cursou nem os nove anos iniciais de ensino; na região norte, o percentual chega a $37,8 \%$.

Já nas regiões sul e sudeste, ocorre o inverso. Nesses estados, o percentual das pessoas que tinham completado pelo menos o ensino médio é superior ao das demais regiões. Na região Sudeste, o índice chega a 59,1\%, e no Sul, $51,8 \%$.

De forma geral, é pequeno o percentual de trabalhadores do país que têm nível superior completo: apenas $16 \%$ das pessoas ocupadas atingiram esse nível. A região Sudeste é a que apresenta o maior nível, com 19,5\%, enquanto a região Norte tem o menor, com 10,5\%.

Esse panorama remete-nos ao pensamento de um grande sociólogo e jurista brasileiro, o Prof. Roberto Lira, que questionava a legitimidade dos pilares do Estado Democrático de Direito, quando afirmava:

[...] com um povo analfabeto não há cidadãos, com um povo faminto e doente não há trabalhadores e soldados, com um povo asfixiado e espoliado não há soberania, com distância e abismos sociais não há unidade, com exploração do homem pelo homem não há ordem nem progresso, com desigualdade não há justiça nem paz (FERREIRA, 1995, pág. 93).

\section{Da Inviabilização das Eleições}

Como exposto, ao invés de solucionarem um problema, criam um de maior gravidade: a inviabilização das eleições em vários municípios, principalmente na região nordeste, na qual há locais com pessoas sem curso superior, e que estariam inaptas a disputar qualquer cargo eletivo com a aprovação dessa PEC.

Há outros argumentos contrários à aprovação da PEC nº 194/2016, porém menos plausíveis: a que afirma que para ser político basta, tão-somente, possuir sabedoria para lidar com questões políticas; a de que na democracia o representante não governa sozinho, sendo desnecessária a formação acadêmica, por ser aquele auxiliado por assessores com curso superior.

Reiteramos: embora seja salutar à democracia que o governo conduzido por cidadãos aptos e preparados, aprovar a PEC no 194/2016 na atual conjuntura educacional do país seria inaplicável, com a consequente inviabilização das eleições em certas localidades, a configurar atentado abissal à democracia brasileira, visto que violaria o princípio representativo, contido no parágrafo único do art. $1^{\circ}$ da Constituição Federal. 


\section{Do Princípio Representativo}

Pelo vetor representativo, todo poder emana do povo, que o exerce por meio de representantes eleitos ou diretamente, nos termos da Constituição, mediante eleições livres e periódicas. Todo poder emana do povo, significa que o regime democrático e o respeito às liberdades públicas constituem a pedra de toque da República Federativa do Brasil, algo que as autoridades públicas devem observar.

Democracia é o governo do povo, para o povo, pelo povo e em benefício dele. Assim, a emanação do poder advém do povo, porque o povo não pode apresentar-se na função de governo. Os seus escolhidos o representam, governando e tomando decisões em seu nome, como se estivessem em seu próprio lugar, exteriorizando a vontade geral.

O poder, contudo, é exercido por meio de representantes eleitos ou diretamente. São os mandatários, ou representantes eleitos pelo povo, os incumbidos de exercer mandatos. Tais mandatos obrigam politicamente os eleitos a agir em benefício dos seus eleitores (do povo), defendendo teses, fórmulas e propostas de campanha.

Curioso observar que o cumprimento do princípio da representatividade deve ser nos termos da Constituição Federal, ou seja, os mandatários do povo devem pautar o exercício de suas atribuições à luz das balizas constitucionais. Exorbitá-las, ou renegá-las a segundo plano, é olvidar a democracia (BULOS, 2008, págs. 395-396).

\section{Do Método para a Elaboração de uma Proposta de Emenda Constitucional}

A proposta de emenda constitucional tem processo de aprovação diferenciado e mais rigoroso do que o das leis ordinárias; trata-se da modificação da lei maior do Estado, portanto, poucos são os que podem exercê-la. Podem apresentar uma PEC, conforme o artigo 60, da Constituição Federal: no mínimo 1/3 dos membros da Câmara dos Deputados ou do Senado Federal; o Presidente da República; ou mais da metade das Assembleias Legislativas das unidades da Federação, manifestando-se, cada uma delas, pela maioria relativa (também chamada maioria simples, isto é, 50\% mais um) de seus membros. 
Inicialmente, o Presidente da Câmara deve enviar a proposta de emenda constitucional à Comissão de Constituição, Justiça e Cidadania (CCJ), que ficará encarregada de examinar a admissibilidade da PEC. Nessa fase, a análise é técnica, e devem ser verificados os requisitos formais e materiais. Se rejeitada nessa fase, a proposta deve ser arquivada. A admissibilidade pode, porém, ser debatida em Plenário caso o autor da proposta consiga as assinaturas de pelo menos $1 / 3$ da composição da Câmara.

Se admitida, a PEC deve ser encaminhada à comissão temporária criada pela Comissão de Constituição, Justiça e Cidadania (CCJ), a qual examinará o seu conteúdo, podendo propor emendas, que também devem ser submetidas ao exame de admissibilidade.

Normalmente as deliberações principais são feitas na Câmara dos Deputados, exceto quando a iniciativa tenha partido do Senado Federal. O quórum para aprovação de uma proposta de emenda constitucional é bastante qualificado, devendo haver aprovação por pelo menos 3/5 dos parlamentares em cada casa do Congresso Nacional.

Além disso, a discussão sobre a PEC ocorrerá em dois turnos, isto é, após a discussão e aprovação por maioria de 3/5, realiza-se uma nova deliberação, para só então a proposta ser encaminhada à casa revisora, onde haverá nova votação em dois turnos. Em caso de alterações à PEC, esta deve voltar à casa originária para ser novamente discutida e votada.

Depois de toda essa maratona, caso a PEC sobreviva, seguirá diretamente para a fase de promulgação e publicação. Isso significa que não há sanção ou veto do Presidente da República em caso de emenda constitucional (diferentemente do que ocorre com os projetos de lei ordinária, por exemplo).

Finalmente, a promulgação e a publicação também não serão feitas pelo Presidente da República, mas pelas Mesas da Câmara dos Deputados e do Senado Federal. Após a publicação no Diário Oficial, a emenda será anexada ao texto constitucional, passando a viger imediatamente, sem a contagem do prazo legal de 45 dias (vacatio legis) previsto no art. 1ㅜㅡ da Lei de Introdução às normas do Direito Brasileiro, salvo se houver disposição expressa definindo prazo diverso. 


\section{Das Limitações ao Poder de Emendar a Constituição}

As limitações ao poder de emendar a Constituição podem ser de dois tipos:

a) Limitações expressas: são aquelas previstas na Constituição, art. 60, e subdividem-se em:

- formais - dizem respeito à adequação do processo legislativo àquilo que a norma dispõe. Por exemplo: podem as assembleias legislativas de somente dois entes da Federação proporem emenda constitucional? Não, pois tal iniciativa fere diretamente ao disposto no artigo 60, da Constituição federal;

- materiais - são as chamadas cláusulas pétreas. Trata-se de limitações à alteração de matérias específicas previstas na própria Constituição Federal (tratadas adiante);

- circunstanciais - consistentes em certas situações nas quais a Constituição Federal não pode ser alterada, como o Estado de sítio, o Estado de defesa e a intervenção federal nos Estados ou Distrito Federal;

- temporais - diz respeito ao prazo estabelecido pela Constituição no qual fica proibida sua alteração. Existiu na Constituição de 1824.

b) Limitações implícitas: são aquelas que não são encontradas explicitamente na Constituição. Referem-se:

- à supressão das limitações expressas - uma emenda constitucional não pode alterar as normas que tratam da própria limitação à alteração das emendas constitucionais;

- ao titular do poder constituinte originário - o poder decorrente não pode sobrepor-se ao poder que o constituiu;

- ao titular do poder constituinte derivado. Significa afirmar que aqueles que têm legitimidade para propor emendas à Constituição (parlamentares, assembleias e Presidente) não podem ser alterados.

As cláusulas pétreas não podem ser alteradas em hipótese alguma sob a ordem constitucional vigente, conforme se infere do $\int 4^{\circ}$ do artigo 60 da Constituição Federal, as definindo, conforme segue: 
Art. 60. A Constituição poderá ser emendada mediante proposta: $[\ldots]$

$\int 4^{\circ}$ Não será objeto de deliberação a proposta de emenda constitucional tendente a abolir:

I. A forma federativa de Estado;

II. O voto direto, secreto, universal e periódico;

III. A separação dos Poderes;

IV. Os direitos e garantias individuais.

\section{Crítica}

Cabe às Comissões de Constituição e Justiça analisar a compatibilidade do projeto de lei ou proposta de emenda constitucional apresentados ao texto da Constituição Federal. O art. 58 da Constituição Federal prevê a criação de comissões, constituídas na forma do respectivo regimento ou do ato que resultar sua criação e com atribuições neles previstas (MORAES, 2010, pág. 718).

Art. 58. O Congresso Nacional e suas Casas terão comissões permanentes e temporárias, constituídas na forma e com as atribuições previstas no respectivo regimento ou no ato de que resultar sua criação.

$\mathrm{O}$ art. 32, inciso IV, do Regimento Interno da Câmara dos Deputados criou a comissão de Constituição, Justiça e de Redação, estabelecendo seu campo temático e sua área de atividade em aspectos constitucionais, legais, jurídicos, regimentais e de técnica legislativa de projetos, emendas ou substitutivos sujeitos à apreciação da Câmara ou de suas comissões, para efeito de admissibilidade e tramitação.

Art. 32. São as seguintes as Comissões Permanentes e respectivos campos temáticos ou áreas de atividade:

$[\ldots]$

IV- Comissão de Constituição e Justiça e de Cidadania:

a) Aspectos constitucional, legal, jurídico, regimental e de técnica legislativa de projetos, emendas ou substitutivos sujeitos à apreciação da Câmara ou de suas Comissões;

b) Admissibilidade de proposta de emenda à Constituição; 
c) Assunto de natureza jurídica ou constitucional que lhe seja submetido, em consulta, pelo Presidente da Câmara, pelo Plenário ou por outra Comissão, ou em razão de recurso previsto neste Regimento;

d) Assuntos atinentes aos direitos e garantias fundamentais, à organização do Estado, à organização dos Poderes e às funções essenciais da Justiça;

e) Matérias relativas a direito constitucional, eleitoral, civil, penal, penitenciário, processual, notarial [...]

Por sua vez, o Regimento Interno do Senado Federal prevê, no art. 101, a existência da Comissão de Constituição, Justiça e Cidadania, com competência para opinar sobre a constitucionalidade, juridicidade e regimentalidade das matérias que lhe forem submetidas por deliberação do plenário, por despacho do Presidente, por consulta de qualquer comissão, ou quando em virtude desses aspectos houver recurso de decisão terminativa de comissão para o plenário.

Acreditamos que a PEC no 194/2016 não será aprovada pela CCJ em razão de infringir o inciso II do art. 60 da Constituição Federal, uma vez que afeta a capacidade eleitoral passiva, abolindo parcialmente o direito de ser votado ao criar uma condição de inelegibilidade, justificada pela elevação do nível intelectual dos parlamentares.

$\mathrm{Na}$ hipótese, caso aprovada, haveria a inviabilização das eleições em diversas cidades brasileiras, em desobediência ao princípio representativo, elencado no parágrafo único do art. 1ํ da Constituição Federal, valendo salientar que a PEC em comento carrega vício de inconstitucionalidade.

Reiteramos: ao suprimir a capacidade eleitoral passiva do cidadão, oriundo de regiões onde há habitantes sem curso superior, a PEC se subsume à limitação constitucional do art. 60, \4², inciso II da CF, cujo teor informa que não será objeto de deliberação a proposta de emenda tendente a abolir o voto direto, secreto, universal e periódico.

Ademais, insta salientar que essa PEC de "cunho tecnocrata" é ineficaz, porque os Tribunais Eleitorais, juntamente com as Câmaras Municipais, promovem cursos preparatórios aos futuros parlamentares, recém empossados, cujo objetivo é orientar os novos parlamentares à realização de suas atividades nas Assembleias, primando pelo bom desempenho. O conteúdo programático contempla questões referentes à legislação muni- 
cipal, técnica legislativa, funcionamento dos poderes, processo legislativo, postura em plenário, relação com a imprensa, sendo igualmente destinado aos assessores.

Exempli gratia, a Resolução nº 08/2000 da Câmara de Vereadores de Cachoeira do Sul-RS, a qual determinou que os 15 vereadores eleitos terão que participar de um curso preparatório com o tema atividade parlamentar.

Os futuros parlamentares da Legislatura 2017/2020 receberão informações e orientações pertinentes à Lei Orgânica do Município e Regimento Interno da Câmara de Vereadores, processo legislativo e técnica legislativa, estrutura organizacional do município, finanças, tributos, orçamento público e sistema único de saúde.

\section{Considerações Finais}

A tecnocracia seria um regime político que os governantes pretensamente atuam como técnicos, não como políticos; suas responsabilidades seriam verificadas por sua eficácia e sua eficiência no atingimento de fins cientificamente estipulados. Buscam a solução para a desordem e a injustiça socioeconômica por meio de conhecimento verdadeiro, superior ao senso comum e detido relativamente por poucos.

Essa ideologia contraria o regime democrático, porque nem os chefes do Executivo nem os integrantes do Legislativo governam de forma isolada; todos possuem assessores, que são nomeados e escolhidos, conforme sua especialidade, para atuarem na área correlata.

É totalmente despicienda a criação de uma norma semelhante à PEC n⿳ 194/2016, uma vez que sua existência configura abissal afronta ao princípio da representatividade, porquanto a condição de elegibilidade por aquela criada inviabilizaria as eleições em diversos municípios devido à elevada taxa de analfabetismo e à inexistência de cidadãos com diploma acadêmico de nível superior.

A exigência de tornar o cidadão elegível desde que possua qualquer curso superior retira sua essência tecnocrata, porque não é todo curso superior que oferece conhecimentos ao exercício da função parlamentar, nada valendo o diploma de um cidadão formado em gastronomia ou em educação física, tendo em vista não possuir habilidade em lidar com proces- 
so legislativo ou competência jurisdicional. Se seguirmos à risca, o governo ficaria restrito apenas aos advogados, aos administradores e aos economistas.

Por fim, vale salientar que os candidatos eleitos de "primeira viagem" frequentam um curso de capacitação, oferecido pela Câmara Legislativa e pelo Tribunal Regional Eleitoral, cujo objetivo é orientá-los no exercício da função parlamentar. Esse curso é fundamental porque auxilia aqueles que nunca assistiram a uma votação no plenário, tampouco têm noção do funcionamento de uma Assembleia Legislativa, por exemplo.

A PEC n 194/2016 deverá ser refutada, porque a educação não pode se tornar pressuposto da democracia, principalmente, quando o próprio Estado não cria condições mínimas nem a oferece dignamente ao povo.

\section{Referências}

BRETAS, Valéria. As 30 cidades onde quase metade da população é analfabeta. Revista Exame, São Paulo, ed. 1097, 09 set. 2015. Disponível em: $<$ http://exame.abril.com.br/brasil/as-30-cidades-onde-quase-metade-da-populacao-e-analfabeta/> Acesso em: 14 set. 2016.

BULOS, Uadi Lammêgo. Curso de direito constitucional. 02 Ed. São Paulo: Saraiva, 2008.

DRUCKER, Peter F. Capitalism Society. New York: Harper Collins. Publishers, 1993.

FACHIN, Zulmar. Coord; Acelino Rodrigues Carvalho. Direitos Fundamentais e Cidadania. São Paulo: Método, 2008.

FERREIRA FILHO, Manoel Gonçalves. Curso de direito constitucional. 31ํㅡㄹ. São Paulo: Saraiva, 2005.

FERREIRA, Pinto. Curso de direito constitucional. 07ª Ed. São Paulo: Saraiva, 1995.

HAMILTON, Alexander; MADISON, James; JAY, John. E1 Federalista. FCE: México,1994.

MONTESQUIEU, Charles de Secondat Baron de. O espírito das leis. Tradução: Cristina Murachco. 03 Ed. São Paulo: Martins Fontes, 2005.

MORAES, Alexandre de. Direito Constitucional. 25ํㅡㄹ. São Paulo: Atlas, 2010. 
MORAES, Cacau. Vereadores eleitos terão que participar de curso preparatório para a atividade parlamentar. Jornal O Correio, São Paulo, 22 nov. 2016. Disponível em: < http://www.ocorreio.com.br/noticias/14438/vereadores-eleitos-terao-curso-para-a-atividade-parlamentar> Acesso em: 02 dez. 2016 NOVELINO, Marcelo. Hermenêutica Constitucional. Editora Jus Podivm. Bahia, 2008.

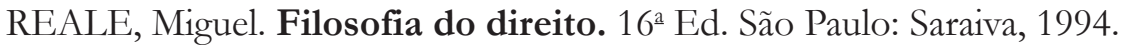

SANCARI, Sebastián. La participación politica en la Argentina contemporánea. 01로 Ed. Ciudad Autónoma de Buenos Aires: La Ley, 2016.

SARTORI, Giovanni. Elementos de teoria política. Alianza: Madrid, 1992. SILVA, José Afonso da. Curso de direito constitucional positivo. $12^{a}$ Ed. São Paulo: Malheiros, 1996.

STRECK, Lenio Luiz. Ciência política e teoria do estado. 07르 Ed. Porto Alegre: Livraria do Advogado, 2010.

TAYLOR, Frederick Winslow. Princípios de administração científica. $08^{a}$ Ed. São Paulo: Atlas, 1990.

Ronaldo de Albuquerque Agra - Especialista em Processo Civil pela UFPE (Universidade Federal de Pernambuco). Especialista em Direito Eleitoral pela ESA/PE (Escola Superior de Advocacia). Aluno do Curso de Doutorado em Processo Constitucional pela UBA (Universidade de Buenos Aires). Advogado. Profissional Liberal. 